\title{
Phacoemulsification with primary implantation of an intraocular lens in patients with uveitis
}

This article was published in the following Dove Press journal:

Clinical Ophthalmology

22 August 2017

Number of times this article has been viewed

\author{
Sara Pålsson ${ }^{1,2}$ \\ Marita Andersson \\ Grönlund ${ }^{1,2}$ \\ Dragana Skiljic ${ }^{1,2}$ \\ Madeleine Zetterberg ${ }^{1,2}$ \\ 'Department of Clinical \\ Neuroscience/Ophthalmology, \\ Institute of Neuroscience and \\ Physiology, Sahlgrenska Academy, \\ University of Gothenburg, \\ Gothenburg, Sweden; ${ }^{2}$ Department \\ of Ophthalmology, Sahlgrenska \\ University Hospital, Mölndal, Sweden
}

Purpose: To evaluate the outcome of cataract surgery in adult patients with uveitis.

Materials and methods: In this retrospective cohort study, medical charts of patients with uveitis and matched control patients without uveitis who underwent cataract surgery at the Eye Clinic, Sahlgrenska University Hospital, Mölndal, between January 2005 and December 2009 were analyzed.

Results: The study included 58 eyes with and 283 eyes without uveitis. The most common etiologies were idiopathic anterior uveitis and Fuchs' heterochromic uveitis. Postoperative visual acuity at 4 weeks was $\geq 0.5$ decimal ( $0.3 \log$ MAR) in 48 eyes with uveitis $(87.3 \%)$ compared to 180 non-uveitic eyes $(86.1 \%)$. Four eyes with uveitis $(7.1 \%)$ and one eye without uveitis $(0.5 \%)$ developed postoperative intraocular hypertension/glaucoma. Posterior capsule opacification developed in 11 eyes $(19.0 \%)$ with and 28 eyes (12.4\%) without uveitis.

Conclusion: With appropriate perioperative anti-inflammatory regimen and surveillance, modern cataract surgery using phacoemulsification and primary intraocular lens implantation can be performed in patients with uveitis without greater risk of complications, yielding similar visual outcome as in patients without uveitis.

Keywords: cataract, intraocular lens, phacoemulsification, uveitis

\section{Introduction}

Cataract in patients with uveitis is common primarily due to the inflammation itself and secondarily due to the treatment of inflammation with steroids. Cataract surgery is more challenging in these patients because of the intraoperative risk factors such as small pupils, posterior synechiae, increased risk of hemorrhage and other associated complications, for example, glaucoma, band keratopathy and cystoid macular edema (CME). ${ }^{1-3}$ An optimal surgical strategy is still under debate, and primary implantation of an intraocular lens (IOL) is not universally accepted. However, according to some studies, modern cataract surgery and optimal perioperative care might result in a satisfactory postoperative outcome in patients with uveitis who undergo primary IOL implantation. ${ }^{4,5}$ Etiologies of uveitis have an impact on prognosis, for example, posterior uveitis is associated with more chorioretinal complications and subsequently is responsible for a less favorable outcome. ${ }^{6,7}$ Till date, there is no consensus on pre-, intra- and postoperative management of patients with uveitis undergoing cataract surgery. Therefore, in this study, we evaluated the results of modern cataract surgery in a cohort of patients with uveitis and compared it with the matched non-uveitic control data during a 5-year period. In addition, we identified the possible predictors of postoperative complications in patients with uveitis.
Correspondence: Madeleine Zetterberg Department of Ophthalmology, Sahlgrenska University Hospital, SE-43I 80 Mölndal, Sweden

Tel +46 3l 3433255

Fax +46 3। 4I 2904

Email madeleine.zetterberg@gu.se 


\section{Materials and methods}

The study protocol was approved by the Regional Ethical Review Board, Gothenburg, and the tenets of the Declaration of Helsinki were followed. Patient consent was not required as this is a retrospective study, and all data were coded prior to statistical analysis. Data of all patients with uveitis, including those with infectious disease and Fuchs' heterochromic cyclitis, who underwent cataract surgery between January 2005 and December 2009 were included. If cataract surgery was performed in both eyes during the study period, then only the right eye was chosen. Patients aged $\leq 16$ years at the time of surgery and patients who underwent combined procedures were excluded. Data of patients without uveitis who underwent cataract surgery the same day by the same surgeon were selected as controls. Medical charts of patients were retrospectively analyzed regarding sex; age at surgery; diagnosis of uveitis; coexisting rheumatic diseases if any; best corrected visual acuity (BCVA); inflammatory status; perioperative treatment and pre-, intra- and postoperative complications. Anatomic classification was made according to Standardization of Uveitis Nomenclature diagnostic criteria. ${ }^{8}$ Snellen charts were used to test BCVA. Postoperative ocular status at 4 and 6 months was registered, and postoperative complications such as posterior capsule opacification (PCO) were noted until last the follow-up.

\section{Pre- and postoperative protocols}

At the Eye Clinic of Sahlgrenska University Hospital, Mölndal, adult patients with juvenile idiopathic arthritis or Behçet's disease are treated preoperatively with oral corticosteroids as a rule. In other types of uveitis, preoperative treatment with steroids is considered in close collaboration with uveitis specialists. Commonly, $30 \mathrm{mg}$ of oral prednisolone is combined with topical corticosteroids such as dexamethasone $0.1 \%$ (Isopto-Maxidex $^{\circledR}$ or Opnol ${ }^{\circledR}$ ) and a nonsteroidal anti-inflammatory drug (NSAID) such as nepafenak $0.1 \%$ $\left(\mathrm{Nevanac}^{\circledR}\right)$ or diklofenak $0.1 \%\left(\right.$ Voltaren ophtha $\left.{ }^{\circledR}\right)$, in a regimen of three to four times daily for 3 days preoperatively. In case of patients with Fuchs' heterochromic cyclitis, therapy with topical corticosteroids and NSAID four times daily is considered sufficient. Patients with herpes-associated uveitis are generally treated preoperatively with aciklovir $400 \mathrm{mg}$ four times daily or with valaciklovir $500 \mathrm{mg}$ two times daily, starting 1 week before surgery and followed for 2 weeks postoperatively.

\section{Surgical technique}

Standard clear corneal phacoemulsification using topical anesthesia was performed. In two uveitic cases and in seven non-uveitic cases, surgery was performed under general anesthesia. Two side-port corneal incisions were made. The primary incision was made with a $2.75 \mathrm{~mm}$ keratome. The anterior chamber was maintained with ophthalmic viscosurgical device (sodium hyalouronate 1.4\%; Healon GV, Abbott Laboratories, IL, USA). Small pupils and posterior synechiae were managed with ophthalmic viscosurgical device and iris retractors (iris hooks) as needed. Trypan blue (VisionBlue, D.O.R.C. Dutch Ophthalmic Research Center, the Netherlands; or Monoblue, Arcadophta, France) was used to stain the anterior capsule in dense cataracts. A $5 \mathrm{~mm}$ anterior continuous curvilinear capsulorhexis was created after which hydrodissection, phacoemulsification and IOL implantation were performed.

\section{Statistical analysis}

Descriptive statistics included mean \pm standard deviation (SD) or median with range as appropriate. Continuous parameters were analyzed with Student's $t$-test and/or Mann-Whitney $U$ test, whereas categorical parameters were analyzed using Fisher's exact test. For change in BCVA after surgery, paired $t$-test was used. All arithmetic procedures on BCVA were performed after conversion to logMAR scale. A $P<0.05$ was considered statistically significant. IBM SPSS Statistics, version 20.0 for Mac (SPSS Inc., Chicago, IL, USA) was used for statistical analysis.

\section{Results}

\section{Demographics and preoperative ocular findings}

A total of 58 eyes with and 225 eyes without uveitis were included. Clinical characteristics are shown in Table 1. Median age at surgery was 60.5 years (range, $30-90$ years) in

Table I Characteristics of patients with and without uveitis undergoing cataract surgery

\begin{tabular}{|c|c|c|c|}
\hline Parameter & $\begin{array}{l}\text { Uveitis } \\
(n=58)\end{array}$ & $\begin{array}{l}\text { No uveitis } \\
(n=225)\end{array}$ & $P$-value \\
\hline \multicolumn{4}{|l|}{ Sex, n (\%) } \\
\hline Female & $35(60.3)$ & $135(60.0)$ & $1.00^{\mathrm{a}}$ \\
\hline Male & $23(39.7)$ & $90(40.0)$ & \\
\hline \multicolumn{4}{|l|}{ Age at surgery, years } \\
\hline Mean (SD) & $61.4(15.6)$ & $69.1(13.5)$ & $<0.00 I^{\mathrm{b}}$ \\
\hline Median (range) & $60.5(30-90)$ & $70.0(27-93)$ & $0.00 \mathrm{I}^{\mathrm{c}}$ \\
\hline Cataract subtype, n (\%) & $(n=58)$ & $(n=2 \mid 7)$ & \\
\hline Cortical & $\mathrm{I}(\mathrm{I} .7)$ & $12(5.5)$ & $0.3 I^{a}$ \\
\hline Posterior subcapsular & $18(31.0)$ & $14(6.5)$ & $<0.00 I^{a}$ \\
\hline Nuclear & $16(27.6)$ & $89(41.0)$ & $0.07^{\mathrm{a}}$ \\
\hline Mixed & $17(29.3)$ & $92(42.4)$ & $0.10^{\mathrm{a}}$ \\
\hline Dense & $6(10.3)$ & $10(4.6)$ & $0.1 I^{a}$ \\
\hline
\end{tabular}

Note: 'Fisher's exact test; 'Student's $t$-test; 'Mann-Whitney $U$ test. Abbreviation: SD, standard deviation. 
the uveitis group and 70.0 (range, 27-93 years) for controls $(P=0.001)$. Majority of the patients, about $60 \%$, were females in both groups. The most common uveitic etiologies were idiopathic anterior uveitis ( $\mathrm{n}=16,27.6 \%)$ and Fuchs' heterochromic uveitis ( $\mathrm{n}=12,20.7 \%)$. Table 2 shows the diagnosis of uveitis, anatomical localization and associated rheumatic disease. The type of cataract differed significantly between uveitic and non-uveitic groups, with posterior subcapsular cataract being more common in the former group: $31.0 \%$ compared to $6.5 \%$, respectively $(P<0.0001)$. Preoperative ocular comorbidity was more common in the uveitic group, both with regard to CME and glaucoma/intraocular hypertension. Preoperative posterior synechiae were present in $22(37.9 \%)$ of the eyes with uveitis, with one of these eyes showing iris bombé. Preoperative ocular findings are shown in Tables 1 and 3.

\section{Pre- and postoperative protocols}

In this study, 25 (43\%) patients with uveitis were preoperatively prescribed with oral corticosteroids with all but one receiving $30 \mathrm{mg}$ prednisolone daily. Topical corticosteroids were prescribed preoperatively for $36(62 \%)$ of the eyes (average 3.4 drops daily); topical NSAID was prescribed for 21 (36\%) eyes (average 3.6 drops daily). All three cases with herpes-related uveitis underwent perioperative antiviral therapy. In the control group, one eye was prescribed

Table 2 Uveitis etiology/associated rheumatic disease and anatomical location

\begin{tabular}{ll}
\hline Systemic and/or ocular diagnosis & $\mathbf{n}(\%)$ \\
\hline Behçet's disease & $\mathrm{I}(\mathrm{I} .7)$ \\
Fuchs' heterochromic uveitis & $12(20.7)$ \\
Herpes-related uveitis & $3(5.2)$ \\
HLA-B27-related uveitis & $2(3.4)$ \\
Idiopathic anterior uveitis & $16(27.6)$ \\
Idiopathic vasculitis & $1(1.7)$ \\
Morbus Bechterew & $6(10.3)$ \\
Polymyalgia/temporalis arteritis & $1(1.7)$ \\
Possner Schlossman & $1(1.7)$ \\
Psoriatic arthritis & $2(3.4)$ \\
Sarcoidosis & $7(12.1)$ \\
SLE & $1(1.7)$ \\
Toxoplasmosis & $2(3.4)$ \\
Ulcerous colitis & I (I.7) \\
Wegener's granulomatosis & $2(3.4)$ \\
\hline Anatomical localization ${ }^{\mathbf{a}}$ & $\mathbf{n}(\%)$ \\
\hline Anterior & $56(96.6)$ \\
Intermediate & $2(3.4)$ \\
Posterior & $4(6.9)$ \\
Pan & 0 \\
\hline
\end{tabular}

Notes: aSome eyes had more than one type of uveitis localization; in one eye, uveitis was mainly posterior. The other eyes with posterior and intermediate uveitis also had anterior uveitis.

Abbreviations: SLE, systemic lupus erythematosus; HLA, human leukocyte antigen.
Table 3 Visual outcome, ocular comorbidity and complications at 4 weeks and 6 months after cataract surgery

\begin{tabular}{|c|c|c|c|}
\hline Parameter & Uveitis & No uveitis & $P$-value \\
\hline \multicolumn{4}{|c|}{$B C V A, \log M A R$, mean $\pm S D$} \\
\hline Preoperatively & $0.63 \pm 0.52$ & $0.6 \mathrm{I} \pm 0.53$ & $0.79^{c}$ \\
\hline 4 weeks & $0.12 \pm 0.18$ & $0.21 \pm 0.37$ & $0.10^{c}$ \\
\hline 6 months & $0.21 \pm 0.29$ & $0.30 \pm 0.54$ & $0.42^{c}$ \\
\hline \multicolumn{4}{|c|}{$\begin{array}{l}\text { BCVA, decimal, median } \\
\text { (range) }\end{array}$} \\
\hline Preoperatively & $0.30(0.00-0.80)$ & $0.40(0.00-1.30)$ & $0.57^{b}$ \\
\hline 4 weeks & $0.80(0.16-1.30)$ & $0.80(0.00-1.30)$ & $0.08^{\mathrm{b}}$ \\
\hline 6 months & $0.80(0.04-1.30)$ & $0.70(0.00-1.30)$ & $0.67^{\mathrm{b}}$ \\
\hline \multicolumn{4}{|c|}{ BCVA, decimal, n (\%) } \\
\hline \multicolumn{4}{|l|}{ Preoperatively } \\
\hline$\geq 0.5$ & $19(34.5)$ & $81(36.5)$ & $0.88^{\mathrm{a}}$ \\
\hline \multicolumn{4}{|l|}{4 weeks } \\
\hline$\geq 0.5$ & $48(87.3)$ & $180(86.1)$ & $1.00^{\mathrm{a}}$ \\
\hline \multicolumn{4}{|l|}{6 months } \\
\hline$\geq 0.5$ & $25(69.4)$ & $27(77.1)$ & $0.59^{a}$ \\
\hline \multicolumn{4}{|l|}{ CME, n (\%) } \\
\hline Preoperatively & $\mathrm{I}(\mathrm{I} .7)$ & 0 & $0.22^{\mathrm{a}}$ \\
\hline 4 weeks & $\mathrm{I}(\mathrm{I} .8)$ & $2(1.0)$ & $0.53^{\mathrm{a}}$ \\
\hline 6 months & 0 & 0 & \\
\hline \multicolumn{4}{|c|}{ Glaucoma treatment, n (\%) } \\
\hline Preoperatively & $7(12.1)$ & $20(8.9)$ & $0.46^{\mathrm{a}}$ \\
\hline 4 weeks & $10(17.9)$ & $20(9.1)$ & $0.09^{a}$ \\
\hline 6 months & $7(I 7.9)$ & $10(13.7)$ & $0.59^{a}$ \\
\hline PCO, n (\%) & II (19.0) & $28(12.4)$ & $0.20^{\mathrm{a}}$ \\
\hline
\end{tabular}

Note: ${ }^{2}$ Fisher's exact test; 'Mann-Whitney $U$ test; 'Student's $t$-test for unpaired groups.

Abbreviations: BCVA, best corrected visual acuity; CME, cystoid macular edema; PCO, posterior capsule opacification.

with preoperative treatment with topical corticosteroids two to three times daily due to episcleritis, and 1 week preoperatively, one eye was prescribed with topical NSAID three times daily. In two uveitic eyes, $20 \mathrm{mg}$ of betamethasone was administered subconjunctivally at the end of the surgical procedure. Postoperatively all patients received topical corticosteroids three to six times daily for at least 3 weeks. For $38(66 \%)$ eyes with uveitis and $23(8 \%)$ eyes in the control group, topical NSAID three or four times daily was prescribed. Oral corticosteroids, if prescribed preoperatively, were tapered during the $2-3$-week period.

\section{Surgical management and complications}

In eight uveitic eyes, synechialysis with ophthalmic viscosurgical device was performed. Iris retractors were used in $9(15.5 \%)$ of the eyes with uveitis and in $12(5.4 \%)$ of the control eyes $(P=0.020)$ (Table 4$)$. In $2(3.3 \%)$ of the uveitic eyes and $40(17.8 \%)$ of the control eyes, a capsular tension ring was inserted $(P=0.004)$. Posterior capsular tear was seen in two eyes in the control group and in none of the uveitic eyes. Several types of IOLs were implanted, most of which were foldable hydrophobic acrylic lenses: Tecnis ZA9003 
Table 4 Intraoperative difficulties and complications

\begin{tabular}{llll}
\hline Parameter & Uveitis & No uveitis & P-value \\
\hline Intraoperative difficulties, $\mathrm{n}(\%)$ & & & \\
$\quad$ Mechanical pupil dilation & $9(15.5)$ & $12(5.4)$ & $0.02^{\mathrm{a}}$ \\
Capsular dye & $\mathrm{I}(1.7)$ & $10(4.4)$ & $0.47^{\mathrm{a}}$ \\
Hooks in rhexis & 0 & $\mathrm{I}(0.4)$ & $1.00^{\mathrm{a}}$ \\
Capsular tension ring & $2(3.3)$ & $40(17.8)$ & $0.004^{\mathrm{a}}$ \\
$\quad$ Total & $12(20.7)$ & $54(24)$ & $0.73^{\mathrm{a}}$ \\
$\begin{array}{l}\text { Intraoperative complications, } \mathrm{n}(\%) \\
\quad \text { Posterior capsular tear }\end{array}$ & 0 & $2(0.9)$ & $1.00^{\mathrm{a}}$ \\
\hline
\end{tabular}

Notes: 'Fisher's exact test; bincluding mechanical pupil dilation, use of capsular dye, iris hooks in rhexis or capsular tension ring.

(Abbott Medical Optics, CA, USA, $n=12$ with uveitis, $n=43$ without uveitis) and Acrysof SN60AT/SN60WF/SA60AT/ MA60AC (Alcon, TX, USA, $n=43$ with uveitis, $n=156$ without uveitis). Some patients received a hydrophilic acrylic lens: Akreos M160, Akreos Adapt AO (Bausch \& Lomb, n=3 with uveitis, $n=15$ without uveitis). Intracameral antibiotics were used in all patients; $1 \mathrm{mg}$ of cefuroxim was used for all eyes except seven patients who received $1 \mathrm{mg}$ vancomycin due to penicillin allergy.

\section{Postoperative complications and visual outcome}

Postoperative complications are described in Tables 3 and 5. Two eyes had increased intraocular pressure at 4 weeks' follow-up which was later normalized with no need for pharmacological treatment. None of the patients in this study developed glaucoma/intraocular hypertension at 6 months' follow-up. Posterior capsule opacification requiring Nd:YAG capsulotomy developed in $11(19 \%)$ eyes with uveitis and in 28 (12.4\%) control eyes $(P=0.204)$. Median follow-up time for patients with uveitis was 54.3 months (range, $0.2-108.9$ months) and 5.1 months (range, $0.2-104$ months) for patients without uveitis. No significant difference in risk of PCO was observed between patients receiving hydrophobic versus hydrophilic IOLs (Table 5). Pre- and postoperative BCVA

Table 5 Hydrophobic and hydrophilic intraocular lenses and PCO in patients with and without uveitis

\begin{tabular}{llll}
\hline IOL-type, $\mathbf{n}(\%)$ & Uveitis & No uveitis & P-value \\
\hline Hydrophobic & $55(94.8)$ & $199(91.7)$ & $0.58^{\mathrm{a}}$ \\
Hydrophilic & $3(5.2)$ & $18(8.3)$ & - \\
\hline PCO, n (\%) & Hydrophobic & Hydrophilic & \\
\hline Yes & $37(14.6)$ & $2(9.5)$ & $0.75^{\mathrm{a}}$ \\
No & $217(85.4)$ & $19(90.5)$ & - \\
\hline
\end{tabular}

Notes: Median follow-up time for patients with uveitis was 54.3 months (range, 0.2-108.9 months) and for patients without uveitis was 5.1 months (range, 0.2-104 months). aFisher's exact test.

Abbreviations: IOL, intraocular lens; PCO, posterior capsule opacification. are shown in Table 3. In 24 eyes with uveitis and in 70 control eyes, BCVA was $\geq 1.0$ decimal ( $\leq 0 \log$ MAR) at 4 weeks' follow-up. Median change in visual acuity was $-0.33 \log$ MAR (range, -3.00 to -0.9 ) in patients with uveitis and -0.30 (range, -3.00 to 2.70 ) in control eyes at 4 weeks' follow-up and $-0.33 \log$ MAR (range, -2.90 to 0.25 ) and -0.21 (range, -2.00 to 1.30 ) at 6 months' follow-up. In one eye in the uveitis group, previously treated with radiation due to a choroidal melanoma, BCVA did not improve after surgery. In three other eyes, BCVA was poor with decimal values of $0.16,0.25$ and 0.3 . This could be explained by posterior segment abnormalities due to vasculitis, diabetic macular pathology, a paracentral chorioretinitis scar after toxoplasmosis and previous surgery for retinal detachment (scleral buckle). In 21 eyes in the control group, BCVA at 4 weeks' follow-up was 0.3 decimal ( $0.52 \log$ MAR) or worse. This poor outcome could be explained by coexisting diabetic retinopathy $(n=2)$, maculopathy $(n=7)$, intraocular hypertension/glaucoma $(\mathrm{n}=2)$, amblyopia $(\mathrm{n}=3)$ or prior surgery for retinal detachment $(n=2)$. In the remaining eyes, BCVA was influenced by recent surgery for retinal detachment $(n=1)$, PCO ( $\mathrm{n}=1), \mathrm{CME} /$ epiretinal membrane requiring surgery $(\mathrm{n}=1)$, reduced ability to communicate (stroke and progressive myoclonic epilepsia) $(\mathrm{n}=2)$, a corneal erosion $(\mathrm{n}=1)$ and incomplete documentation $(\mathrm{n}=1)$.

\section{Discussion}

Cataract surgery in patients with uveitis is considered more challenging than surgery in patients with age-related cataract in general. Poor control of inflammation pre- and postoperatively increases the risk of complications. Abbouda et al showed that chronic postoperative inflammation and more than one relapse in 1 year was highly associated with macular edema. ${ }^{9}$ Other factors that may influence the outcome include etiology, anatomical localization, surgical approach and type of IOL. ${ }^{6}$ The importance of control of preoperative inflammation has been emphasized in several studies, and a good control of inflammation at least 3 months prior to the operation has been recommended. ${ }^{3-5,10,11}$ Table 6 summarizes previous reports on this topic.

Uveitis is a risk factor in the development of cataract; in this retrospective study, patients with uveitis were found to be significantly younger at surgery than patients without uveitis $(P<0.001)$, which is in accordance with other reports. ${ }^{12}$ In addition, we found that the most common etiologies were Fuchs' heterochromic uveitis and idiopathic anterior uveitis. A similar distribution has been shown in previous studies. ${ }^{11,13}$ 


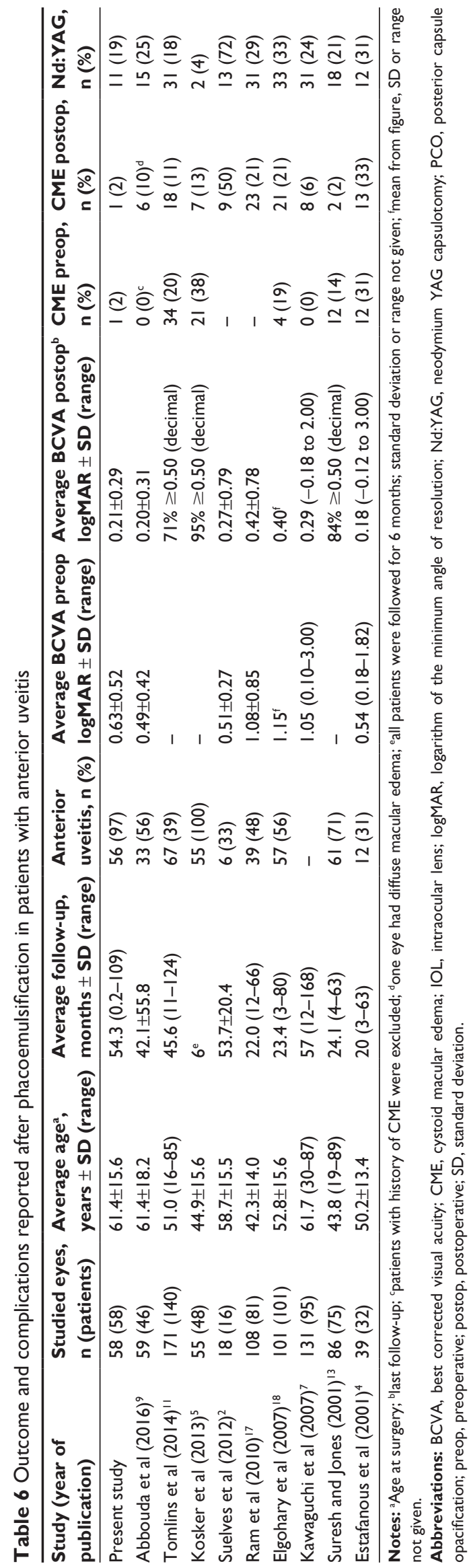

According to the data, preoperative glaucoma was seen in $20(8.9 \%)$ control eyes and in $7(12.1 \%)$ uveitic eyes. The incidence of uveitic glaucoma varies and has been described to occur in the range of $4 \%-19 \%$, which agrees with the results of this study. However, the risk of developing glaucoma is dependent on factors such as uveitic etiology and duration, and in some uveitic groups, the incidence of glaucoma has been reported close to $100 \% .^{14,15}$ Few patients with uveitis had a history of CME compared to previous studies. ${ }^{1,16}$ As expected, posterior synechiae was only seen in eyes with uveitis, resulting in more frequent need of intraoperative mechanical pupil dilation. However, we did not find a significant difference in intraoperative complications between the two groups.

Postoperative glaucoma in eyes without previous intraocular hypertension or glaucoma developed in a few more eyes in the uveitis group; four eyes (7.1\%) with uveitis and one eye $(0.5 \%)$ without uveitis. Other studies have shown similar occurrence of postoperative intraocular hypertension or glaucoma in patients with uveitis, $4.6 \%,{ }^{17} 5.9 \%{ }^{18}$ and $8.4 \%$. $^{7}$ However, as previously noted, none of the patients in this study developed glaucoma/intraocular hypertension that required treatment at 6 months' follow-up. Thus, our study indicates that a thorough monitoring of IOP especially in the close postoperative period is important in patients with uveitis.

In contrast to previous studies, there were few cases of postoperative development of CME: $1(1.8 \%)$ eye with uveitis and $2(1.0 \%)$ eyes without uveitis. ${ }^{12}$ This might reflect the etiology of uveitis, with few eyes showing CME prior to surgery and good preoperative control of inflammation. However, since optical coherence tomography is not performed postoperatively as a routine in our clinic, this condition may have been underdiagnosed. Similar to previous studies, ${ }^{18,19}$ in this study, PCO was found to be the most common postoperative complication, as seen in $11(19.0 \%)$ eyes with uveitis and 28 (12.4\%) eyes without uveitis. Although this difference was not significant, probably due to the relatively small uveitic cohort, the higher incidence of PCO in the uveitis group is well in line with other studies, reporting a higher risk of PCO in patients with uveitis. ${ }^{17}$

Visual acuity improved in both groups after surgery, with postoperative BCVA $\geq 0.5$ decimal ( $0.3 \log \mathrm{MAR})$ in $48(87.3 \%)$ eyes in the uveitis group and in $180(86.1 \%)$ eyes in the control group. Possible explanations for the good visual outcome is that many of the patients with uveitis in this study showed predominantly anterior uveitis without complications in posterior segment and that inflammation was optimally 
controlled preoperatively. In three cases in the uveitis group with poor postoperative BCVA, two of the eyes had abnormalities in the posterior segment related to uveitis.

There are some limitations of this study. First, is the retrospective design resulting in sparse information in some cases. Second, some patients had a short follow-up period which may have resulted in underestimation of postoperative complications. However, we believe that if complications affecting vision had occurred in these patients, they would most likely have consulted their ophthalmologist. Third, all patients with uveitis undergoing cataract surgery during the study period were included. This is both a strength and a limitation; only a small number of patients with uveitic experienced complications, which may be why this study could not demonstrate any major differences in complications for patients with uveitis versus patients without uveitis. Finally, most of the patients with uveitis had anterior idiopathic uveitis and Fuchs' heterochromic uveitis, something that may have resulted in a low complication rate and good outcome. However, we believe that this study gives a representative picture of the patients with uveitis subjected to cataract surgery at a fairly big tertiary referral center.

\section{Conclusion}

This study demonstrates that despite a higher rate of preoperative ocular comorbidity in uveitic eyes, the outcome and rate of complication rate after phacoemulsification with primary IOL implantation are similar in patients with or without uveitis. This in turn demonstrates that modern cataract surgery is beneficial and safe in patients with uveitis when employing a meticulous pre- and postoperative antiinflammatory regime. This study also shows that poor visual outcome is primarily related to complications in posterior segment such as vasculitis, diabetic macular pathology, toxoplasmosis and previous retinal detachment.

\section{Acknowledgments}

This work was supported by grants from the Sahlgrenska University Hospital ("Agreement concerning research and education of doctors"; ALFGBG-441721), Göteborg Medical Society, Marianne and Marcus Wallenberg Foundation, Dr Reinhard Marcuses Foundation, Konung Gustaf V:s och Drottning Victorias Frimurarestiftelse, Hjalmar Svensson Foundation, Greta Andersson Foundation, Herman Svensson Foundation, Ögonfonden, De Blindas Vänner and Kronprinsessan Margaretas Arbetsnämnd för Synskadade.

\section{Disclosure}

The authors report no conflicts of interest in this work.

\section{References}

1. Jones NP. The Manchester Uveitis Clinic: The first 3000 patients, 2: Uveitis Manifestations, Complications, Medical and Surgical Management. Ocul Immunol Inflamm. 2015;23(2):127-134.

2. Suelves AM, Kruh JN, Aznar-Peña I, Siddique SS, Foster CS. Longterm safety and visual outcomes of anterior chamber intraocular lens implantation in patients with a history of chronic uveitis. $J$ Cataract Refract Surg. 2012;38(10):1777-1782.

3. Jancevski M, Foster CS. Cataracts and uveitis. Curr Opin Ophthalmol. 2010;21(1):10-14.

4. Estafanous MF, Lowder CY, Meisler DM, Chauhan R. Phacoemulsification cataract extraction and posterior chamber lens implantation in patients with uveitis. Am J Ophthalmol. 2001;131(5):620-625.

5. Kosker M, Sungur G, Celik T, Unlu N, Simsek S. Phacoemulsification with intraocular lens implantation in patients with anterior uveitis. J Cataract Refract Surg. 2013;39(7):1002-1007.

6. Mehta S, Linton MM, Kempen JH. Outcomes of cataract surgery in patients with uveitis: a systematic review and meta-analysis. $\mathrm{Am} \mathrm{J}$ Ophthalmol. 2014;158(4):676-692.e7.

7. Kawaguchi T, Mochizuki M, Miyata K, Miyata N. Phacoemulsification cataract extraction and intraocular lens implantation in patients with uveitis. J Cataract Refract Surg. 2007;33(2):305-309.

8. Jabs DA, Nussenblatt RB, Rosenbaum JT; Standardization of Uveitis Nomenclature (SUN) Working Group. Standardization of uveitis nomenclature for reporting clinical data. Results of the First International Workshop. Am J Ophthalmol. 2005;140(3):509-516.

9. Abbouda A, Tortorella P, Restivo L, Santoro E, De Marco F, La Cava M. Follow-up study of over three years of patients with uveitis after cataract phacoemulsification: outcomes and complications. Semin Ophthalmol. 2016;31(6):532-541.

10. Foster CS, Rashid S. Management of coincident cataract and uveitis. Curr Opin Ophthalmol. 2003;14(1):1-6.

11. Tomlins PJ, Sivaraj RR, Rauz S, Denniston AK, Murray PI. Longterm biocompatibility and visual outcomes of a hydrophilic acrylic intraocular lens in patients with uveitis. J Cataract Refract Surg. 2014; 40(4):618-625.

12. Bélair ML, Kim SJ, Thorne JE, et al. Incidence of cystoid macular edema after cataract surgery in patients with and without uveitis using optical coherence tomography. Am J Ophthalmol. 2009;148(1): 128-135.e2.

13. Suresh PS, Jones NP. Phacoemulsification with intraocular lens implantation in patients with uveitis. Eye (Lond). 2001;15(Pt 5): 621-628.

14. Bettis DI, Morshedi RG, Chaya C, Goldsmith J, Crandall A, Zabriskie N. Trabeculectomy with mitomycin $\mathrm{C}$ or Ahmed valve implantation in eyes with uveitic glaucoma. J Glaucoma. 2015;24(8):591-599.

15. Neri P, Azuara-Blanco A, Forrester JV. Incidence of glaucoma in patients with uveitis. J Glaucoma. 2004;13(6):461-465.

16. Groen F, Ramdas W, de Hoog J, Vingerling JR, Rothova A. Visual outcomes and ocular morbidity of patients with uveitis referred to a tertiary center during first year of follow-up. Eye (Lond). 2016;30(3): $473-480$.

17. Ram J, Gupta A, Kumar S, Kaushik S, Gupta N, Severia S. Phacoemulsification with intraocular lens implantation in patients with uveitis. $J$ Cataract Refract Surg. 2010;36(8):1283-1288.

18. Elgohary MA, McCluskey PJ, Towler HM, et al. Outcome of phacoemulsification in patients with uveitis. Br J Ophthalmol. 2007; 91(7):916-921.

19. Agrawal R, Murthy S, Ganesh SK, Phaik CS, Sangwan V, Biswas J. Cataract surgery in uveitis. Int J Inflam. 2012;2012:548453. 
Clinical Ophthalmology

\section{Publish your work in this journal}

Clinical Ophthalmology is an international, peer-reviewed journal covering all subspecialties within ophthalmology. Key topics include: Optometry; Visual science; Pharmacology and drug therapy in eye diseases; Basic Sciences; Primary and Secondary eye care; Patien Safety and Quality of Care Improvements. This journal is indexed on

PubMed Central and CAS, and is the official journal of The Society of Clinical Ophthalmology (SCO). The manuscript management system is completely online and includes a very quick and fair peer-review system, which is all easy to use. Visit http://www.dovepress.com/ testimonials.php to read real quotes from published authors. 